\title{
Refractive and visual results and patient satisfaction after excimer laser photorefractive keratectomy for myopia
}

Eye, Ear and Throat Hospital, Shrewsbury B L Halliday Accepted for publication 17 May 1995

\begin{abstract}
A study of excimer laser photorefractive keratectomy was performed on 108 patients. Variation in individual refractive outcome was noted, particularly for the higher levels of correction. At 12 months, of those with up to 3 dioptres of myopia, $93 \%$ were within 1 dioptre of emmetropia, $100 \%$ achieved an acuity of $6 / 12$ unaided, $69 \%$ were very pleased with their result, and $10 \%$ were very disappointed. Of those with between 3.1 and 6 dioptres of myopia, the respective figures were $75 \%, 73 \%$, $65 \%$, and $11 \%$. For those with over 6 dioptres of myopia the respective figures were $46 \%, 58 \%, 38 \%$, and $23 \%$. Some patients were disappointed despite having achieved good unaided visual acuity. Forty seven per cent of patients lost at least one Snellen line of best corrected acuity. Glare was a problem for some of the time in over $60 \%$. Perceived distortion of vision was a problem for all of the time in $11 \%$ to $31 \%$ of cases depending on the initial level of myopia. In some cases the refraction continued to change between 12 months and 20 months.
\end{abstract}

(Br F Ophthalmol 1995; 79: 881-887)

Superficial corneal ablation with an excimer laser to correct myopia (photorefractive keratectomy or PRK) is a technique that is now widely available with dozens of lasers in the United Kingdom. Careful laser calibration and pretreatment quality control measures both help ensure that the computer guided corneal ablation is precise. Healing after surgery is usually associated with regression so most patients are treated to give initial hyperopia with the aim of final emmetropia. The healing process is almost invariably associated with the development of some degree of corneal haze visible at biomicroscopy. ${ }^{12}$ In many patients this haze appears to resolve completely but in others it persists for at least 1 year from surgery, ${ }^{23}$ and may develop into a scar dense enough to obscure completely details of intraocular structures. ${ }^{4} \mathrm{~A}$ relation has been suggested between the amount of haze and the degree of regression, ${ }^{1}$ and haze may be more of a problem with the deeper ablations used to correct higher levels of myopia. ${ }^{5}$ As well as haze, regression may be associated with an increase in central corneal thickness which may return to, or beyond, preoperative levels. ${ }^{6}$

It is essential that patients are counselled adequately before they decide to proceed with surgery. Inevitably patients hope for a good result and prior knowledge of all possible problems may not prevent postoperative disappointment if the result is poor. This study presents a series of patients, with both objective results (refraction and visual acuity) and the subjective opinions of the patients as expressed via a questionnaire. The results were analysed to give the sensitivity and specificity of the objective measurements as indicators of patient satisfaction.

\section{Patients and methods}

The patients included in this study were all treated privately at one laser centre (Corneal Laser Centre, Clatterbridge Hospital, Bebington, Wirral). The usual route of referral was via the laser centre. Patients who responded to advertisements or other laser centre publicity were sent a brochure and invited to give details of a recent refraction to the clerical staff at the centre. Patients who were then considered potentially suitable for PRK, and who lived in my catchment area, were given my name, address, and telephone number and invited to contact me for a consultation.

\section{CONSULTATION}

The consultation included history, clinical examination, and an explanation about the laser and the possible outcomes of surgery. A standard report form was used to ensure a uniform approach to patients and in particular to make sure that a comprehensive explanation was given to every patient. The history included spectacle and contact lens history with specific inquiry about recent changes in refraction. The routine clinical examination included measurement of visual acuities, biomicroscopy, fundus examination, and manifest refraction. Patients with more than 1.5 dioptres of astigmatism were excluded from treatment. Visual acuity was recorded using a Snellen chart up to the $6 / 4$ line. Patient explanation included the number of years that laser treatment had been available and the fact that it was an experimental procedure. Every patient was told that the operation could cause permanent corneal scarring with loss of best corrected acuity and that glare could interfere with vision. Warnings were also given about delay in obtaining a stable result and about the problems with anisometropia should treatment not be performed on the second eye. The approximate percentage chances of obtaining 
an uncorrected acuity of $6 / 12$ and $6 / 6$ were given. A practical demonstration was then given using trial lenses. Patients were shown the effect of spherical correction for their myopia (astigmatism correction was not attempted in these cases) and also shown the effect of over and undercorrection (usually by 1 dioptre). An explanatory letter was then sent to the patient's general practitioner in advance of any proposed treatment date.

\section{TREATMENT}

The Summit Technology UV 200 excimer laser was used. The wavelength was $193 \mathrm{~nm}$, the fluence was $180 \mathrm{~mJ} / \mathrm{cm}^{2}$, the pulse repetition rate $10 \mathrm{~Hz}$, and the treatment zone $5 \mathrm{~mm}$ diameter. After the administration of a miotic and topical anaesthesia, a speculum was inserted in the treatment eye and the fellow eye was occluded. The patient was positioned under the laser and alignment confirmed with helium-neon aiming beams. Two practice runs of the laser were then given; first firing onto a methylcellulose artificial tear film and then onto corneal epithelium. The corneal epithelium was then removed mechanically and the treatment was given. In every case the goal of treatment was emmetropia. In some cases (eyes with over 6 dioptres of myopia treated before a software modification was available) two successive laser applications were given at the treatment session.

\section{POSTOPERATIVE MANAGEMENT}

After treatment a mydriatic eyedrop and an antibiotic ointment were applied to the eye which was then padded. Oral analgesia was given. The next day the pad was removed and chloramphenicol ointment prescribed twice a day for 4 days. At the same time a steroid eyedrop (fluoromethalone $0 \cdot 1 \%$ ) was started, used initially four times a day. These drops were tailed off over a period of 6-8 weeks after surgery. Patients were reviewed again within a few days of surgery, then at about 1 week to check epithelial healing. At later visits patients were refracted. The refractive result was converted to a spherical equivalent and recorded. The magnitude of the astigmatism was also recorded without regard to axis.

\section{INTERVENTION TREATMENTS}

Three types of intervention were employed for patients who had a poor refractive result; steroid eyedrops, redo surgery, and repeat removal of corneal epithelium. Dexamethasone $0.1 \%$ eyedrops were prescribed for some cases of myopia, tailing off over a period of weeks. ${ }^{7}$ In other cases of myopia redo laser surgery was performed. Repeat laser was only considered if the reduced visual acuity was a serious handicap to the patient and if the refraction was stable on two successive follow up visits. It was performed in the same way as the initial treatment with mechanical removal of the corneal epithelium and the laser set to correct $100 \%$ of the residual myopia. For those who remained hyperopic after their laser surgery and who could not accommodate comfortably to overcome this, epithelial debridement was used. ${ }^{8}$ In these cases it was postulated that the steroids used after laser ablation may have limited regression by inhibiting epithelial cell replication. ${ }^{9}$ After administration of topical anaesthesia the epithelium was removed using a scalpel blade and the eye padded for 24 hours. Antibiotic drops or ointment were then prescribed for a few days; steroids were not used.

\section{QUESTIONNAIRE}

One year after surgery, patients were sent a questionnaire asking for their views. They were asked which one of the following best matched their overall view of surgery:

Absolutely delighted

Very pleased

Fairly pleased

Not particularly pleased but not particularly disappointed

Fairly disappointed

Very disappointed

Bitterly disappointed and regret ever having had surgery

They were also asked to indicate if either glare or distortion of vision was a problem for some of the time, all of the time, or none of the time, and also if the vision in the operated eye was good enough to manage without spectacles or contact lenses for some of the time, all of the time, or none of the time. Finally they were invited to make any comments on the operation and its result.

\section{Results}

The study group consisted of 108 consecutive first eyes treated by the author. The 68 female and 40 male patients had an average age of 35 years (range 21 to 66 years). The initial level of myopia was in the range from -1.25 to -3 dioptres in 19 cases, $-3 \cdot 1$ to -6 dioptres in 63 cases, and $-6 \cdot 1$ to -11 dioptres in the remaining 26 cases. Of the patients treated for over 6 dioptres of myopia, nine required two successive treatments while 17 cases were treated after the software modification allowed single application ablation.

Long term refractive and visual results were available on 90 cases $(83 \%)$ with an average period of follow up of 17 months (range 9 to 24 months). To enable direct comparison with other studies, results are reported from the ' 1 year' follow up visit. On average this visit was 55 weeks from surgery. In 45 patients a late follow up result was available at an average of 87 weeks (20 months) from surgery. One hundred and six patients (98\%) completed the questionnaire.

\section{EPITHELIAL HEALING}

Corneal epithelialisation was uneventful and complete before 1 week in every case. One patient presented 6 weeks after surgery with an acutely painful eye and was found to have a 
Table 1 Discrepancy in refraction with respect to emmetropia at 1 year for each refractive group (\%)

\begin{tabular}{|c|c|c|c|}
\hline \multirow{2}{*}{$\begin{array}{l}\text { Discrepancy from } \\
\text { emmetropia (D) }\end{array}$} & \multicolumn{3}{|c|}{ Initial myopia (D) } \\
\hline & $-1 \cdot 25$ to -3 & $-3 \cdot 1$ to -6 & $-6 \cdot 1$ to -11 \\
\hline $\begin{array}{l}\text { Within } 0.5 \\
\text { Within 1 } \\
\text { Within 2 }\end{array}$ & $\begin{array}{r}57 \\
93 \\
100\end{array}$ & $\begin{array}{l}60 \\
75 \\
81\end{array}$ & $\begin{array}{l}29 \\
46 \\
62\end{array}$ \\
\hline
\end{tabular}

small corneal abrasion associated with microcysts in the treated eye. The eye was padded for 24 hours and lubricant ointment used for 1 month. Eight patients reported occasional transient minor ocular pain, usually on waking, as late as 13 months from surgery. No clinical abnormality was found and no treatment was given. Intraocular pressure was checked while patients were on steroid eyedrops; in one patient a pressure of $30 \mathrm{~mm} \mathrm{Hg}$ was recorded, this returned to normal when steroid drops were discontinued.

ONE YEAR REFRACTIVE AND VISUAL RESULTS Most patients were overcorrected at 3-8 weeks and then regressed towards emmetropia. Variation was noted in refractive outcome between individual patients. Some patients showed very little regression, while others regressed back to the original level of myopia. Every refractive result (as spherical equivalent) was plotted on a graph (Fig 1). Each line represents an individual patient. Patients who had intervention with dexamethasone eyedrops are shown with arrows on their lines representing the period of treatment. Patients who had redo laser surgery are shown with a dotted line from the time of the repeat surgery and those who had epithelium removal for hyperopia are shown with a broken line from the time that this was done.

Table 1 shows the 1 year refractive results with the percentage of patients within each refractive range. Three target ranges are given: within $0.5,1$, and 2 dioptres of emmetropia.

Table 2 shows the uncorrected visual acuity at 1 year. The results are shown as cumulative percentages so that the percentage achieving any given level of acuity can be read off the table.

Table 3 shows patients who lost best corrected acuity at 1 year. Patients who had redo laser surgery or epithelium removal before their 1 year examination are excluded from this table. This exclusion was made as these interventions cause a temporary reduction in best

Table 2 Cumulative uncorrected visual acuity at 1 year for each refractive group (\%)

\begin{tabular}{|c|c|c|c|}
\hline \multirow{2}{*}{$\begin{array}{l}\text { Uncorrected } \\
\text { visual acuity }\end{array}$} & \multicolumn{3}{|c|}{ Initial myopia (D) } \\
\hline & $-1 \cdot 25$ to -3 & $-3 \cdot 1$ to -6 & $-6 \cdot 1$ to -11 \\
\hline $\begin{array}{l}6 / 4 \\
6 / 5 \\
6 / 6 \\
6 / 9 \\
6 / 12 \\
6 / 18 \\
6 / 24 \\
6 / 36 \\
6 / 60 \\
\text { Counting fingers }\end{array}$ & $\begin{array}{r}14 \\
43 \\
71 \\
86 \\
100\end{array}$ & $\begin{array}{r}10 \\
15 \\
42 \\
69 \\
73 \\
88 \\
\\
90 \\
92 \\
100\end{array}$ & $\begin{array}{r}12 \\
37 \\
58 \\
71 \\
79 \\
\\
83 \\
100\end{array}$ \\
\hline
\end{tabular}

corrected visual acuity which would have distorted the figures. A total of 39 patients lost one or more lines of best corrected visual acuity. The majority of these still had an acuity of $6 / 6$ or better at 1 year with just 14 of the 39 patients ending up with an acuity of $6 / 9$ or worse. These 14 were as follows: nine patients lost two lines of vision (seven to $6 / 9$, one to $6 / 12$, and one to $6 / 18$ ) and five lost one line of vision (four to $6 / 9$ and one to $6 / 12$ ).

Increased magnitude of astigmatism (by at least 1 dioptre) at 1 year compared with the preoperative value was seen in seven patients. Again, those who had redo laser surgery or epithelium removal were excluded from this analysis. The increased astigmatism was $2 \cdot 25$ dioptres in one case; in the remainder the average increase was $1 \cdot 1$ dioptres.

\section{REFRACTIVE AND VISUAL CHANGES AFTER 1 YEAR}

For those patients who did not have refractive intervention (steroid drops, redo laser, or epithelium removal) the results of the late follow up examination (20 months) were compared with the 1 year visit. For the two lowest levels of initial myopia the refractive change averaged less than $0 \cdot 25$ dioptres (maximum of 0.875 dioptres of continued regression and $1 \cdot 12$ dioptres of increased effect). For the highest range of initial myopia $(-6 \cdot 1$ to -11 dioptres) there was an average change of 0.42 dioptres of continued regression with a maximum of 1.37 dioptres of increased myopia.

Unaided visual acuity at the late follow up examination was unchanged in $46 \%$ of cases. In $25 \%$ of cases it improved and in $29 \%$ it worsened. For those who did experience a change, the average was 1.4 lines of the Snellen chart.

\section{RESULTS OF INTERVENTION TREATMENTS}

Graphical demonstration of the effect of these manoeuvres is shown in Figure 1. Five patients were treated with dexamethasone drops for a period of 6 to 20 weeks as treatment for regression. In every case there was a reduction in myopia (average 1.6 dioptres). At the final follow up visit (on average 38 weeks after stopping the drops) four patients had fallen back to or beyond the original level of regression, but one patient maintained improvement from a refraction of -1 dioptre to $-0 \cdot 125$ dioptre at 23 weeks after stopping the drops.

Eight patients had redo laser treatment. Their initial myopia was in the range from $-5 \cdot 25$ to -9 dioptres. At the time of retreatment their average refraction was -3 dioptres. At the final follow up visit (on average 40

Table 3 Loss in best corrected acuity at 1 year for each refractive group (\%)

\begin{tabular}{llll}
\hline \multirow{2}{*}{$\begin{array}{l}\text { Loss of best corrected } \\
\text { visual acuity }\end{array}$} & \multicolumn{3}{l}{ Initial myopia (D) } \\
\cline { 2 - 4 } & $-1 \cdot 25$ to -3 & $-3 \cdot 1$ to -6 & $-6 \cdot 1$ to -11 \\
\hline No loss & 54 & 52 & 50 \\
One Snellen line & 38 & 29 & 35 \\
Two Snellen lines & 8 & 19 & 15 \\
\hline
\end{tabular}



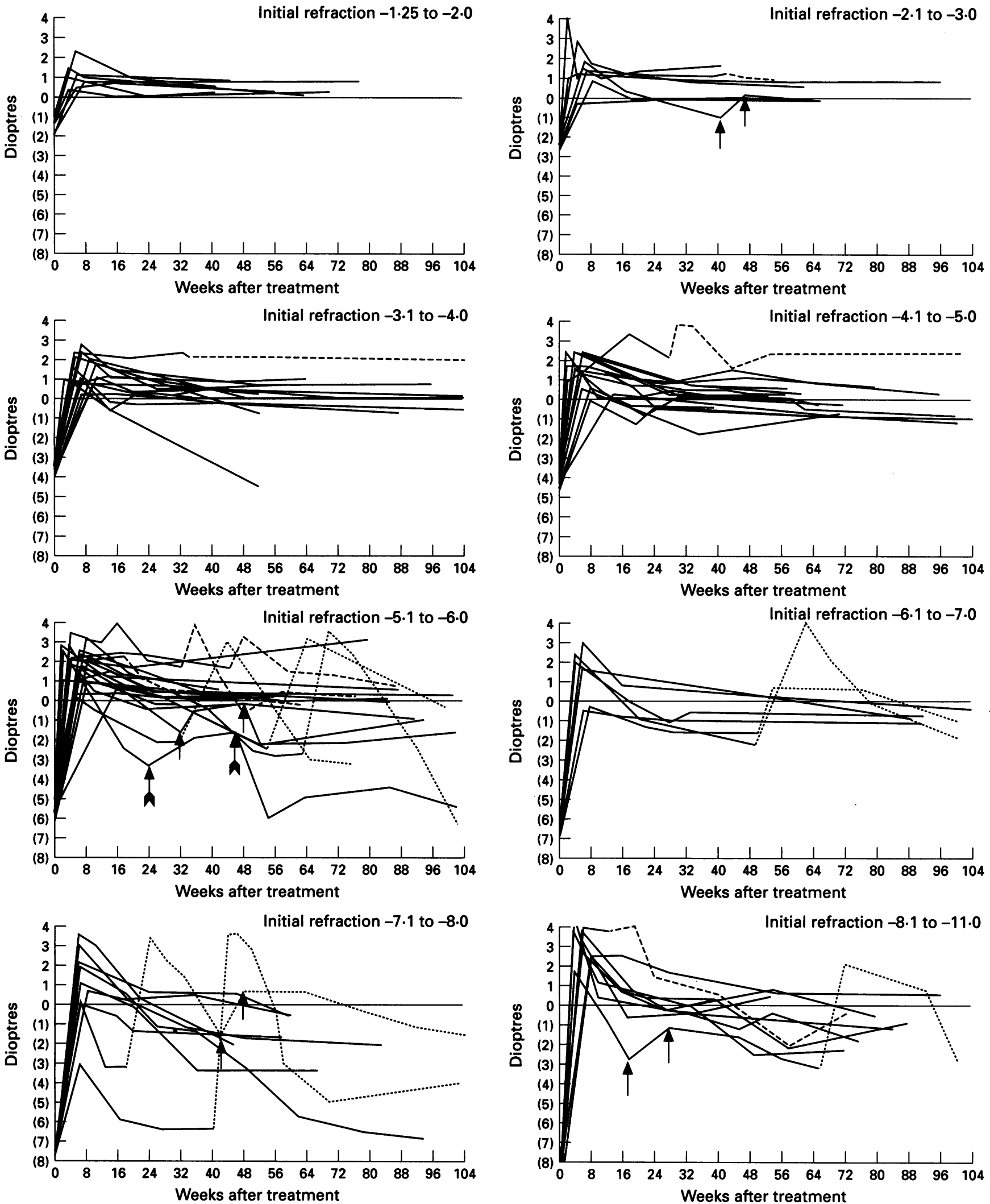

Figure 1 Spherical equivalent of refraction (dioptres) plotted for each patient against time from surgery (weeks). Dioptres of myopia are shown in parentheses. Each individual line represents one patient. Dotted line indicates results after redo laser treatment, broken line indicates results after removal of epithelium, arrows indicate period of treatment with topical dexamethasone $0 \cdot 1 \%$.

weeks after the repeat laser) two patients had a level of myopia worse than that before retreatment. Six patients did have some reduction of myopia, but in every case there was continued regression. On average only $37 \%$ of the desired correction was maintained in these six patients (range $14 \%$ to $77 \%$ ). After retreatment five patients had an unaided acuity of $6 / 60$ or less, the remaining three patients had acuities of $6 / 36,6 / 18$, and $6 / 9$ respectively.

Seven patients had removal of epithelium for hyperopia. At the time of epithelium removal the average refraction was $+2 \cdot 4$ dioptres. At the final follow up visit (on average 42 weeks after the epithelium was removed) the average refraction was +0.71 dioptres. Three patients 
Table 4 Questionnaire results at 1 year for each refractive group regarding satisfaction with the procedure (\%)

\begin{tabular}{llll}
\hline & \multicolumn{3}{l}{ Initial myopia $(D)$} \\
\cline { 2 - 4 } & $-1 \cdot 25$ to -3 & $-3 \cdot 1$ to -6 & $-6 \cdot 1$ to -11 \\
\hline Absolutely delighted & 53 & 29 & 15 \\
Very pleased & 16 & 36 & 23 \\
Fairly pleased & 16 & 15 & 27 \\
Neither pleased nor disappointed & 5 & 6 & 12 \\
Fairly disappointed & & 6 & 19 \\
Very disappointed & 10 & 5 & 4 \\
Bitterly disappointed & & & \\
\hline
\end{tabular}

Table 5 Questionnaire results at 1 year for each refractive group regarding presence of glare, distortion of vision, and ability to manage without refractive correction (\%)

\begin{tabular}{llll}
\hline & Initial myopia (D) & \\
\cline { 2 - 4 } & $-1 \cdot 25$ to -3 & $-3 \cdot 1$ to -6 & $-6 \cdot 1$ to -11 \\
\hline Never glare & 37 & 29 & 23 \\
Sometimes glare & 63 & 63 & 62 \\
Always glare & 0 & 8 & 15 \\
Never distortion & 63 & 37 & 11 \\
Sometimes distortion & 26 & 48 & 58 \\
Always distortion & 11 & 15 & 31 \\
Always need refractive correction & 6 & 15 & 34 \\
Sometimes no refractive correction & 26 & 25 & 35 \\
Never need refractive correction & 68 & 60 & 31 \\
\hline
\end{tabular}

experienced an improvement in unaided visual acuity. The first of these improved from $6 / 12$ to $6 / 6$ as hyperopia reduced from $+1 \cdot 125$ dioptres to +0.875 dioptres, the second improved from $6 / 18$ to $6 / 9$ as hyperopia reduced from +2.25 dioptres to -0.37 dioptres myopia, and the third patient improved from $6 / 18$ to $6 / 6$ as the hyperopia reduced from +1.875 dioptres to $+0 \cdot 125$ dioptres.

\section{QUESTIONNAIRE RESULTS}

Tables 4 and 5 show the answers given to the specific questions on the questionnaire. Many patients volunteered comments on their operation. Most of these were positive and a representative sample of these are shown in Table 6. Twenty five patients (24\%) made negative comments and quotes from all 25 are shown in Table 7. Both Table 6 and Table 7 group patients according to initial myopia and show the unaided acuity at the time that the questionnaire was completed.

Not all patients with good vision were pleased with the result of surgery; indeed some who had an uncorrected acuity of better than

Table 6 Positive comments made by patients at 1 year for each refractive group. Each comment is from a different patient. The unaided visual acuity at the time of the comment is shown

\begin{tabular}{|c|c|}
\hline $\begin{array}{l}\text { Unaided } \\
\text { visual } \\
\text { acuity }\end{array}$ & Comments \\
\hline \multicolumn{2}{|c|}{ Initial myopia $-1 \cdot 25$ to $-3 \mathrm{D}$} \\
\hline $6 / 5$ & $\begin{array}{l}\text { I was very, very pleased with the result of this operation and now find it hard to } \\
\text { believe that I was ever short sighted }\end{array}$ \\
\hline \multicolumn{2}{|r|}{ Initial myopia $-3 \cdot 1$ to $-6 \mathrm{D}$} \\
\hline $6 / 6$ & $\begin{array}{l}\text { I would recommend anyone to have this operation - I am totally delighted and very } \\
\text { satisfied with the results }\end{array}$ \\
\hline $6 / 4$ & $\begin{array}{l}\text { Overall I could not be more pleased with the results of both eyes. I have disposed of } \\
\text { my contact lenses completely }\end{array}$ \\
\hline $\begin{array}{l}6 / 12 \\
6 / 9 \\
6 / 5 \\
\text { Initial }\end{array}$ & $\begin{array}{l}\text { To be able to see without glasses was well worth the money and the pain } \\
\text { Overall I am very pleased with the results and would recommend people to go for it } \\
\text { The whole procedure was quick, painless and has lived up to expectations } \\
\text { ia }-6 \cdot 1 \text { to }-11 \mathrm{D}\end{array}$ \\
\hline $\begin{array}{l}6 / 9 \\
6 / 12 \\
6 / 12\end{array}$ & $\begin{array}{l}\text { I would recommend the operation to any short sighted person } \\
\text { I can see the clock when I wake in the morning } \\
\text { I am very pleased with the results of the operation }\end{array}$ \\
\hline
\end{tabular}

6/12 were very disappointed owing to problems with glare or distortion. The ability of refractive and visual results to identify patients who were very pleased with treatment was analysed. An unaided visual acuity of $6 / 12$ or better identified patients who were very pleased (or absolutely delighted) with a sensitivity of $94 \%$ and a specificity of $50 \%$. Using $6 / 6$ as the benchmark, the sensitivity was $49 \%$ and the specificity was $82 \%$. A refractive result within 1 dioptre of emmetropia was $90 \%$ sensitive and $55 \%$ specific and a result within 0.5 dioptres was $69 \%$ sensitive and $71 \%$ specific.

\section{Discussion}

This study found that the majority of patients who had PRK had uneventful epithelial healing, achieved a good unaided acuity, had a refractive result close to emmetropia, and were pleased with the result. A number of patients were disappointed; either with an inaccurate refractive result or with subjectively poor quality of vision. None suffered from any serious vision threatening complications. This is an advantage compared, for example, with radial keratotomy where complications causing legal blindness have been recorded. ${ }^{10}$

The refractive and visual results in this study are similar to some other reports of PRK. In this study $93 \%$ of those with up to -3 dioptres of initial myopia and $75 \%$ of those with between $-3 \cdot 1$ and -6 dioptres were within 1 dioptre of emmetropia at 1 year. This is comparable with other series where the overall percentages within 1 dioptre have been reported as $63 \%,{ }^{1} 71 \%,{ }^{11} 79 \%,{ }^{12} 79 \%,{ }^{13}$ $80 \%,{ }^{14} 86 \%,{ }^{15}$ and $93 \%{ }^{3}$ For unaided visual acuity, this study found $100 \%$ of those with up to -3 dioptres of initial myopia and $73 \%$ of those with between $-3 \cdot 1$ and -6 dioptres achieved at least $6 / 12$. Comparable studies have reported overall figures of $72 \%,{ }^{1} 89 \%,{ }^{13}$ $91 \%,{ }^{15} 94 \%,{ }^{14}$ and $98 \%{ }^{3}$

Patients with over 6 dioptres of myopia had either one or two successive laser treatments. Separate analysis of these two groups was performed and showed no clear advantage; on one hand the one treatment group appeared better with more patients within 1 dioptre of emmetropia, more who never needed refractive correction, and fewer disappointed with the procedure, but on the other hand the two treatment groups also appeared better with more patients who achieved $6 / 6$ or $6 / 12$ unaided, fewer who lost best corrected visual acuity, and more who were pleased with the procedure. As neither technique was convincingly superior and as the numbers in each group were small, making separate analysis questionable, the results of the two groups were combined.

Loss of best corrected acuity occurred in $47 \%$ of patients in this study. This is a higher figure than reported in some other series and may partly be due to the fact that visual acuity was recorded to a level of $6 / 4$. One study that recorded acuity to a level of $6 / 5$ found that $15 \%$ of patients lost best corrected visual acuity. ${ }^{2}$ Two studies that recorded acuities to 
Table 7 Negative comments made by patients at 1 year for each refractive group. Each comment is from a different patient. The unaided visual acuity at the time of the comment is shown ( $C F=$ counting fingers)

\begin{tabular}{|c|c|}
\hline $\begin{array}{l}\text { Unaided } \\
\text { visual } \\
\text { acuity }\end{array}$ & Comments \\
\hline \multicolumn{2}{|c|}{ Initial myopia $-1 \cdot 25$ to $-3 \mathrm{D}$} \\
\hline $6 / 6$ & $\begin{array}{l}\text { Reading for long periods is a problem. Glare is present more than when I wore con- } \\
\text { tact lenses }\end{array}$ \\
\hline $\begin{array}{l}6 / 6 \\
6 / 12 \\
\text { Initial my }\end{array}$ & $\begin{array}{l}\text { I feel badly let down ... I feel I have been the subject of some experimentation } \\
\ldots \text { wish never had laser done } \\
\text { pia }-3 \cdot 1 \text { to }-6 D\end{array}$ \\
\hline CF & $\begin{array}{l}\text { I now have a permanent haze which blurs everything far and near. I no longer drive } \\
\text { at night because of the increased glare }\end{array}$ \\
\hline $6 / 9$ & I have double vision \\
\hline $6 / 6$ & $\begin{array}{l}\text { Vision for night driving is so poor that I will not have my other eye treated. Reading } \\
\text { vision is much poorer in the treated eye }\end{array}$ \\
\hline CF & $\begin{array}{l}\text {... has proved bitterly disappointing ... exacerbated by the extensive scarring giving } \\
\text { cloudy vision }\end{array}$ \\
\hline $\begin{array}{l}6 / 18 \\
6 / 36\end{array}$ & $\begin{array}{l}\text { Recovery of vision was lengthy and continued to fall back even after } 6 \text { months } \\
\text { My operation wasn't very successful }\end{array}$ \\
\hline $\begin{array}{l}6 / 6 \\
6 / 9\end{array}$ & $\begin{array}{l}\text { I find night driving rather difficult as I do experience a lot of glare from headlights } \\
\text { My biggest problem is with glare ... the eye itself seems to have been weakened con- } \\
\text { siderably. I would not consider having my other eye treated }\end{array}$ \\
\hline $6 / 9$ & $\begin{array}{l}\text { I was very disappointed with the result of the laser treatment as now I am in a worse } \\
\text { position than before }\end{array}$ \\
\hline $6 / 9$ & $\begin{array}{l}\ldots \text { impossible to obtain suitable glasses for my present situation - that is, short } \\
\text { sighted right eye and long sighted left eye }\end{array}$ \\
\hline CF & ... very unhappy \\
\hline $6 / 18$ & ... didn't live up to expectations \\
\hline \multicolumn{2}{|c|}{ Initial myopia $-6 \cdot 1$ to $-11 \mathrm{D}$} \\
\hline $\begin{array}{l}6 / 9 \\
6 / 24\end{array}$ & $\begin{array}{l}\text { My vision took around } 6 \text { months to recover. Glare is a problem with night driving } \\
\text { I am now stuck with an eye which ... cannot be corrected to give me the vision I had } \\
\text { before the operation with spectacles ... double vision which is always there }\end{array}$ \\
\hline $6 / 12$ & $\begin{array}{l}\text { Although the sight in my eye has improved, it has not improved enough to make the } \\
\text { operation worthwhile }\end{array}$ \\
\hline CF & I am concerned with glare and very poor night vision \\
\hline CF & I am disappointed that my eye did not work even after two attempts \\
\hline $\begin{array}{l}6 / 18 \\
6 / 18\end{array}$ & $\begin{array}{l}\text { I have trouble with glare, distortion, and double vision } \\
\ldots \text { haze always a problem especially in artificial light night driving impossil }\end{array}$ \\
\hline CF & $\begin{array}{l}\ldots \text { my right eye is now very poor and no help to me at all ... my quality of life has } \\
\text { deteriorated since the operation. }\end{array}$ \\
\hline $6 / 18$ & ... horrendous glare \\
\hline
\end{tabular}

$20 / 15$, found that $18 \%$ and $24 \%$ lost best corrected Snellen acuity with the maximum loss recorded as three lines. ${ }^{13}$ In the current study the majority of those who lost best corrected vision still had an acuity of $6 / 6$ or better; only $17 \%$ ended up with an acuity of $6 / 9$ or worse and no one lost more than two lines of vision. In some occupations this loss of best corrected acuity could be important. It is noteworthy that some investigators have not found this loss of best corrected acuity, with figures as low as $0.4 \%$ and $0 \%$ of patients losing vision. ${ }^{14} 16$

Little change was found in the refractive result in the period from 1 year to 20 months for the lowest ranges of myopia treated, but there was an average of 0.42 dioptres of continued regression seen in the 26 patients with the highest range of myopia $(-6 \cdot 1$ to -11 dioptres). While some reports have not found this continued regression, ${ }^{17}$ others have found regression continuing from 1-2 years after surgery, ${ }^{16}$ and it remains to be seen if this regression will be a clinical problem in excimer laser patients.

In some cases of poor refractive results, intervention treatments were used. While this study was not designed to evaluate these, some conclusions can be reached. Topical dexamethasone did reduce myopia in every case that it was used, but the effect was generally not sustained. Although steroid treatment has been reported to be helpful, ${ }^{7}$ the current study supports those where its use did not appear to be of benefit. ${ }^{2} 18$ Redo laser treatment did have some effect, but marked regression was seen in every case so the final clinical benefit was limited. Previous studies have also shown that some patients end up with increased myopia after retreatment, ${ }^{4}$ and that the average outcome can be regression back to myopia. ${ }^{4} 19$ Epithelium removal for hyperopia did appear to have some benefit in three out of seven patients treated. It is impossible to be sure that the beneficial effect was due to the removal of epithelium, but there were no complications and the procedure deserves consideration.

The questionnaire showed that between $15 \%$ and $23 \%$ of patients (depending on initial degree of myopia) were disappointed with their result. A majority of patients found that both glare and distortion of vision were a problem for some of the time and a few described difficulty in driving at night (Table 7). Problems with glare, night halos, and blurred vision have been found in other studies but they tend to diminish with time. ${ }^{121420}$ Persistent problems with night driving have also been reported. ${ }^{20}$

In some cases an apparently good refractive or visual result was marred by subjectively poor quality of vision. Of the 25 patients (approximately one quarter of the study group) who chose to make negative comments (Table 7), no less than 11 of them had unaided acuities of $6 / 12$ or better.

An adverse healing response after PRK can result in focal corneal scarring and irregularities, ${ }^{21} 22$ and there is commonly a reduction in contrast sensitivity. ${ }^{21423}$ It may be that these factors reduce the quality of vision even when the unaided acuity is good.

This study has shown that the objective measures of 6/12 unaided acuity and 1 dioptre of refractive error are poor predictors of success as defined by response to a questionnaire. Although the 6/12 target did successfully identify $94 \%$ of those who were very pleased with surgery (sensitivity), the specificity of this test was only $50 \%$. In other words, $50 \%$ of those who were not very pleased, had that opinion of surgery despite having achieved an unaided acuity of $6 / 12$. Similarly poor specificity was found using a refractive target of result within 1 dioptre of emmetropia. The more demanding criteria of $6 / 6$ unaided acuity and refraction within 0.5 dioptre did produce better specificity $(82 \%$ and $71 \%$ ) but this was at the cost of poorer sensitivity ( $49 \%$ and $69 \%$ respectively).

Excimer laser surgery is still a relatively new procedure. It appears to be safe, especially when compared with other refractive surgery procedures, but the predictability is only fair and dissatisfied patients are seen in every refractive group. It would seem sensible for surgeons to discourage treatment at the higher levels of myopia and to ensure that in all cases the potential benefits, as perceived by the patient, sufficiently outweigh the possible complications to justify treatment.

1 Gartry DS, Kerr-Muir M, Marshall J. Excimer laser photorefractive keratectomy 18 month follow-up. Ophthalmology 1992; 99: 1209-19.

2 Ficker LA, Bates AK, Steele ADMcG, Lyons CJ, Milliken $\mathrm{AB}$, Astin C, et al. Excimer laser photorefractive keratectomy for myopia: 12 month follow-up. Eye 1993; 7: tomy for

3 Talley AR, Hardten MD, Sher NA, Kim MS, Doughman DJ, Carpel E, et al. Results one year after using the 193 $\mathrm{nm}$ excimer laser for photorefractive keratectomy in mild 
to moderate myopia. Am $\mathcal{f}$ Ophthalmol 1994; 118: 304-11.

4 Epstein D, Tengroth B, Fagerholm P, Hamberg-Nystrom $H$. Excimer retreatment of regression after photorefractive keratectomy. Am ₹ Ophthalmol 1994; 117: 456-61.

5 Heitzmann J, Binder PS, Kassar BS, Nordan LT. The correction of high myopia using the excimer laser. Arch rection of high myopia using the

6 Sabetti L, Spadea L, Furcese N, Balestrazzi E. Measurement of corneal thickness by ultrasound after photorefractive keratectomy in high myopia. $\mathcal{F}$ Refract Corneal Surg 1994; 10: A211-6.

7 Fitzsimmons TD, Fagerholm P, Tengroth B. Steroid treatment of myopic regression: acute refractive and topographic changes in photorefractive keratectomy patients. Cornea 1993; 12: 358-61.

8 Durrie DS, Lesher MP, Hunkeler JD. Treatment of overcorrection after myopic photorefractive keratectomy. $f$ Refract Corneal Surg 1994; 10: S295.

9 Burstein NL. Corneal cytotoxicity of topically applied drugs, vehicles and preservatives. Surv Ophthalmol 1980; 25: $15-30$

10 O'Day DM, Feman SS, Elliott JH. Visual impairment following radial keratotomy. Ophthalmology 1986; 93: 319-26.

11 Brancato R, Tavola A, Carones F, Scialdone A, Gallus G, Garancini $\mathrm{P}$, et al. Excimer laser photorefractive keratectomy for myopia: results in 1165 eyes. Refract Corneal Surg 1993; 9: 95-104.

12 O'Brart DPS, Gartry DS, Lohmann CP, Kerr-Muir MG, Marshall J. Excimer laser photorefractive keratectomy for myopia: comparison of 4.00 and 5.00 millimeter ablation zones. $\mathcal{F}$ Refract Corneal Surg 1994; 10: 87-94

13 Maguen E, Salz JJ, Nesburn AB, Warren C, Macy JI, Papaioannou $\mathrm{T}$, et al. Results of excimer laser photorefractive keratectomy for the correction of myopia. Ophthalmology 1994; 101: 1548-56.
14 Dutt S, Steinert RF, Raizman MB, Puliafito CA. One year results of excimer laser photorefractive keratectomy for low to moderate myopia. Arch Ophthalmol 1994; 112: 1427-36.

15 Tengroth B, Epstein D, Fagerholm P, Hamberg-Nystrom $H$, Fitzsimmons TD. Excimer laser photorefractive keratectomy for myopia. Clinical results in sighted eyes. tectomy for myopia. Clinical res

16 Epstein D, Fagerholm P, Hamberg-Nystrom H, Tengroth B. Twenty-four-month follow-up of excimer laser photorefractive keratectomy for myopia. Refractive and visual acuity results. Ophthalmology 1994; 101: 1588-63.

17 Epstein D, Hamberg-Nystrom H, Fagerholm P, Tengroth B. Stability of refraction 18 months after photorefractive keratectomy with excimer laser. Klin Monatsbl Augenheilkd 1993; 202: 245-8.

18 Steele ADMcG. Excimer laser photorefractive keratectomy. Results with the Summit excimer UV200 and the VISX $20 / 20$ lasers. Effects of steroids on regression. Eur $\mathcal{f}$ Implant Refract Surg 1994; 6: 171-3.

Implant Refract Surg 1994; 6: 171-3.
19 Lawless MA, Cohen PR, Rogers CM. Retreatment of undercorrected photorefractive keratectomy for myopia. $\mathcal{F}$ Refract Corneal Surg 1994; 10: S174-7.

20 O'Brart DPS, Lohmann CP, Fitzke FW, Klonos G, Corbett MC, Kerr-Muir MG, et al. Disturbances in night vision after excimer laser photorefractive keratectomy. Eye 1994, 8: $46-51$.

21 Maguire L, Bechara S. Epithelial distortions at the ablation zone margin after excimer laser photorefractive keratectomy for myopia. Am $¥$ Ophthalmol 1994; 117: 809-10.

22 Aron-Rosa $\mathrm{D}$. Central islands - a puzzling phenomenon associated with excimer laser photorefractive keratectomy in myopic patients. Eur $¥$ Implant Refract Surg 1994; 6: in my.

23 Ambrosio G, Cennamo G, de Marco R, Loffredo L, Rosa $\mathrm{N}$, Sebastiani A. Visual function before and after photorefractive keratectomy for myopia. $\mathcal{\exists}$ Refract Corneal Surg 1994; 10: 129-36. 